\title{
Comparison of pharmacist and public views and experiences of community pharmacy medicines- related services in England
}

This article was published in the following Dove Press journal:

Patient Preference and Adherence

9 September 2016

Number of times this article has been viewed

\author{
Ruth M Rodgers \\ Shivaun M Gammie \\ Ruey Leng Loo \\ Sarah A Corlett \\ Janet Krska \\ Medway School of Pharmacy, \\ The Universities of Greenwich and \\ Kent, Chatham Maritime, UK
}

Background: Services provided by community pharmacists designed to support people using medicines are increasing. In England, two national services exist: Medicine Use Reviews (MUR) and New Medicines Service (NMS). Very few studies have been conducted seeking views of the public, rather than service users, on willingness to use these services or expectations of these services, or determined whether views align with pharmacist perceptions.

Objective: To compare the perceptions of pharmacists and the general public on medicinesrelated services, particularly MUR and NMS services.

Methods: Two parallel surveys were conducted in one area of England: one involved the general public and was administered using a street survey, and the other was a postal survey of community pharmacists. Similar questionnaires were used, seeking views of services, awareness, reasons for using services, and perceived benefits.

Results: Response rates were 47.2\% (1,000/2,012 approached) for the public and 40.8\% $(341 / 836)$ for pharmacists. Few people had experienced a discussion in a private consultation room or were aware of the two formal services, although their willingness to use them was high. Pharmacists estimated time spent on service provision as 10 minutes for MUR and 12 minutes for NMS, which aligned with acceptability to both pharmacists and the public. Pharmacists underestimated the willingness of the public to wait for an informal discussion or to make appointments for formal services. Both pharmacists and the public had high expectations that services would be beneficial in terms of increasing knowledge and understanding, but public expectations and experiences of services helping to sort out problems fell well below pharmacists' perceptions. People who had experienced a pharmacy service had different perceptions of pharmacists.

Conclusion: Views differed regarding why people use services and key aspects of service delivery. For services to improve, the pharmacy profession needs a better awareness of what the public, especially those with potential to benefit from services, view as acceptable and desirable.

Keywords: community pharmacy, public opinion, pharmacist perceptions, medicines-related services

\section{Introduction}

Community pharmacists are increasingly being commissioned to provide cognitive services to support and improve medicines use, such as the Home Medicine Review (HMR) service in Australia and Medication Therapy Management (MTM) services in the US. In England, the Medicines Use Review (MUR) service was introduced in 2005 and by 2014/15, 3.2 million MURs were provided by $93.5 \%(10,916)$ of community pharmacies in England. ${ }^{1}$ This service aims to improve patients' knowledge and use of medicines and help reduce
Correspondence: Janet Krska

Medway School of Pharmacy,

The Universities of Greenwich and Kent,

Chatham Maritime, Kent ME4 4TB, UK

Tel +44 I634202950

Fax +4401634883827

Email j.krska@kent.ac.uk 
medicines wastage. Changes in 2011 require that at least half the MURs provided must be targeted toward patients with respiratory disease, those taking high-risk medicines (nonsteroidal anti-inflammatory drug, anticoagulant, antiplatelet, or diuretic) and those recently discharged from a hospital.

An early evaluation found that $93 \%$ of pharmacists viewed the MUR as potentially improving patients' use of medicines, including adherence and cost-effectiveness, ${ }^{2}$ believing that patients would want pharmacists to review their medicines. Later in-depth work suggested that MURs were poorly integrated into pharmacy workflow, most being provided on an ad hoc basis, conducted with people using few medicines, in part due to dispensing pressures and target numbers imposed by employers. ${ }^{3}$

Most studies seeking the views of patients or pharmacists on the MUR service have been small scale, ${ }^{2,4-8}$ showing that patients seldom request an MUR, most are initiated by pharmacists and patients feel obliged to undergo one to help the pharmacist. An in-depth study of MUR consultations found that the experience did not increase patients' knowledge and it rarely affected medicine use. ${ }^{3}$ These findings echo earlier work showing that patients were ambivalent about receiving a medicines management consultation with a pharmacist, viewing it as providing reassurance. ${ }^{9}$

A second formal service, the New Medicines Service (NMS), was introduced in England in 2011, targeted toward patients with asthma, COPD, diabetes, hypertension, or taking an antiplatelet/anticoagulant, aiming to help reduce symptoms and complications of these conditions and identify any related issues, including the need for further information and support. The service involves two or three consultations, only the first of which should be face-to-face interaction. A total of 775,998 NMS were provided by 9,308 (79.7\%) English community pharmacies in $2014 / 15 .^{1}$ An evaluation of this service found that pharmacists considered it as an opportunity to educate and support patients, while patients were unaware of it, but viewed it positively once experienced. ${ }^{10}$

Studies in several countries suggest that awareness of medicines-related cognitive services among the general public is limited. In Australia and the US, both awareness and expectations of these services are low. ${ }^{11}$ Being worried about medicines was a potential motivating factor for using the Australian HMR service, ${ }^{12}$ whereas in Sweden people taking-up offers of pharmaceutical care services were "worried, vulnerable, and information-seeking". ${ }^{13}$ Australians considered improving ability to manage medicines, reducing concerns, and increasing knowledge were further motivating factors for having a HMR, but their expectations that the review would achieve these was low. ${ }^{14}$ The Royal Pharmaceutical Society in the UK has highlighted the need for greater public awareness of pharmacy services. ${ }^{15}$

Most studies of medicines-related services provided by community pharmacists have obtained views of service users rather than the public. ${ }^{16-18}$ No work has determined views on people's willingness to make appointments, how much time they are willing to spend discussing their medicines with a pharmacist, and the use of consultation rooms for medicinesrelated services, although leaflets promoting services mention the need to book a consultation with a pharmacist. ${ }^{19}$ Moreover, no studies have compared the views of the public with pharmacists' perceptions of these English medicine services.

This study therefore aimed to obtain the perceptions and experiences of both pharmacists and the general public on medicines-related services in general and specifically on MUR and NMS services, and compare pharmacist and public perceptions.

\section{Methods}

Two surveys were conducted in parallel, one involving the general public and the other community pharmacists, between September and December 2012, following approval from Medway School of Pharmacy Research Ethics committee. Members of the public provided verbal consent and the pharmacist questionnaire contained a statement that consent was implied by its return.

\section{Questionnaire development and piloting} Public questionnaire

A previously validated questionnaire seeking public views on pharmacy public health services ${ }^{20}$ was adapted using findings from focus groups seeking public views on medicines-related services, together with relevant literature and the team's experience. ${ }^{17}$ It included mostly closed questions covering: use of pharmacies, medicines and of medicines-related services, awareness of services, expectations and willingness to use services, reasons for using services and perceived benefits, as well as questions covering specific aspects, such as data sharing, appointments, and waiting times (Supplementary materials). Open questions sought additional reasons for using services and not using pharmacies to seek advice about medicines. Demographic data included gender, age, ethnicity, educational level, and postcode for assessment of deprivation status.

\section{Pharmacist questionnaire}

This was developed using findings from focus groups that included both the public and community pharmacists, 
ensuring overlap with the public questionnaire to enable comparisons. The questionnaire covered pharmacists' views and experiences of providing medicine advisory services and their perceptions of the aspects included in the public questionnaire (Supplementary materials). Open-ended questions sought views on reasons people may use services and whether different services are needed. Demographic data included gender, years qualified, role in pharmacy, pharmacy type and location, and estimated MUR and NMS service delivery.

\section{Piloting}

For the public survey, 25 members of the public known to researchers completed the questionnaire using an interviewer-assisted method, recording time for completion, and questioning about ease of use and understanding. Five pharmacists known to the team, working outside the study area, were asked to complete and return the pharmacist questionnaire by post, with additional questions to assess the ease of use. Minor amendments were made to both questionnaires in the light of comments received.

\section{Recruitment and data collection}

\section{Public survey}

This survey was conducted using interviewer-assisted completion by ten students who had received training to ensure a consistent approach. The questionnaires were completed face-to-face with members of the public recruited at high street locations in ten towns in one county in South East England (Kent). The towns were selected to include subjects from differing socioeconomic and deprivation status. A quota sampling method, based on 2011 census data, was used to ensure that the sample was representative of the county in terms of gender and age, with a target of 100 participants per town. Passers-by were approached by a researcher and invited to participate. Initial screening questions excluded people $<18$ years of age and qualified or trainee health care professionals. The number who declined to complete the survey was recorded.

\section{Pharmacist survey}

This was administered as a postal questionnaire sent to all 836 community pharmacies in three counties in South East England (Kent, Surrey, and Sussex). Nonresponders received a second mail and a telephone call with a further copy of the questionnaire, if requested.

\section{Data analysis}

Data were analyzed using SPSS v22 (IBM Corporation, Armonk, NY, USA). Use of medicines by the public was dichotomized into any or none, and frequency of pharmacy use was dichotomized into frequent (at least once per month) or infrequent (less than once a month/never). Chi-squared tests were used to assess differences in responses between pharmacists and public to similar questions and to evaluate the effect of medicines and pharmacy use on experiences of and willingness to use services. Missing data were excluded from analysis. Due to the large number of comparisons made, a $P$-value of $<0.001$ was regarded as statistically significant. Free-text responses to open-ended questions were categorized and quantified.

\section{Results \\ Response rates and demographic characteristics}

The response rate for the public questionnaire was $47.2 \%$ (1,000 from 2,012 people approached) and $40.8 \%$ (341) for the pharmacist questionnaire after second mailing and telephone reminder. The public were reasonably representative of the population of Kent in terms of gender, age, ethnicity, and deprivation status: $52.7 \%$ (526) were females, $21.8 \%$ (218) were aged $\geq 65$ years, $712(72.3 \%)$ were white, and there was an adequate distribution across five deprivation quintiles. Demographic details are shown in Table 1, along with use of pharmacies, medicines, and general health status. Regular pharmacy use was associated with both older age and regular medicines use $(P<0.001)$.

Pharmacist respondent characteristics are shown in Table 2, plus self-reported estimated frequency of MUR and NMS provision in the previous month.

\section{Experiences of medicines-related services}

The most common reasons selected by the public for using a pharmacy were to have a prescription dispensed (850; $85.1 \%$ ) or to buy medicines $(791 ; 79.2 \%)$, but getting advice on medicines or minor health problems was also selected by over two thirds $(664 ; 66.5 \%$ and $660 ; 66.1 \%$, respectively).

Experiences of different ways of receiving medicinesrelated advice and sharing of information are shown in Table 3, together with willingness to accept these aspects of services in future. The most frequent way in which advice about medicines received was across the counter, with only $28.8 \%$ (288) indicating they had received advice about medicines collected in a private consultation room and only $19.4 \%$ (194) for a new medicine (indicating experience of the NMS). Only one-quarter $(248 ; 24.9 \%)$ had experienced a review of all their medicines in a private room (indicating experience 
Table I Demographic details of public respondents

\begin{tabular}{|c|c|c|}
\hline Characteristic & $\begin{array}{l}\text { Number } \\
\text { (\%) }\end{array}$ & $\begin{array}{l}\text { Kent } \\
\text { population (\%) }\end{array}$ \\
\hline \multicolumn{3}{|l|}{$\operatorname{Sex}(n=999)$} \\
\hline Female & $526(52.7)$ & $51.6 *$ \\
\hline Male & $473(47.3)$ & $48.4^{*}$ \\
\hline \multicolumn{3}{|l|}{ Age group $(n=1,000)$} \\
\hline$<25$ & $140(14.0)$ & $26.9 *$ \\
\hline $25-34$ & $140(14.0)$ & \\
\hline $35-44$ & $170(17.0)$ & $51.0 *$ \\
\hline $45-54$ & $175(17.5)$ & \\
\hline $55-64$ & $157(15.7)$ & \\
\hline 65 and over & $218(21.8)$ & $22.1 *$ \\
\hline \multicolumn{3}{|l|}{ Ethnicity $(n=985)$} \\
\hline White & $712(72.3)$ & $93.0 * *$ \\
\hline Asian & $112(11.4)$ & $3.6 * *$ \\
\hline Black & $90(9.1)$ & $1.3 * *$ \\
\hline Mixed & $62(6.3)$ & $1.6 * *$ \\
\hline Other & $9(0.9)$ & $0.5^{* *}$ \\
\hline \multicolumn{3}{|l|}{ Deprivation status $(n=920)$} \\
\hline I (highest) & $157(17.1)$ & 20.5 \\
\hline 2 & $166(18.0)$ & 20.2 \\
\hline 3 & $172(18.7)$ & 19.9 \\
\hline 4 & $223(24.2)$ & 19.8 \\
\hline 5 (lowest) & $202(22.0)$ & 19.7 \\
\hline Educational level $(n=992)$ & & $\mathrm{n} / \mathrm{a}$ \\
\hline None/primary/secondary & $314(3 \mid .7)$ & \\
\hline Further education & $315(31.8)$ & \\
\hline Bachelor/higher degree & $319(32.2)$ & \\
\hline Current student & $44(4.4)$ & \\
\hline Employment status $(\mathrm{n}=985)$ & & $\mathrm{n} / \mathrm{a}$ \\
\hline Full-time employed & $4 I I(4 I .7)$ & \\
\hline Part-time employed & $196(19.9)$ & \\
\hline Retired & $212(2 \mid .5)$ & \\
\hline Not working & $166(16.9)$ & \\
\hline \multicolumn{2}{|c|}{ Use of prescribed medicines $(n=1,000)$} & $\mathrm{n} / \mathrm{a}$ \\
\hline None & $395(39.5)$ & \\
\hline$\leq 4$ & $376(37.6)$ & \\
\hline $5-8$ & $172(17.2)$ & \\
\hline$>8$ & $57(5.7)$ & \\
\hline \multicolumn{2}{|l|}{ Use of pharmacies ( $n=999)$} & $\mathrm{n} / \mathrm{a}$ \\
\hline More than once a month & $136(13.6)$ & \\
\hline Once a month & $373(37.3)$ & \\
\hline Once every $2-3$ months & $258(25.8)$ & \\
\hline Less than every 3 months & $91(9.1)$ & \\
\hline Never use/do not know & $14 \mid(\mid 4.1)$ & \\
\hline
\end{tabular}

Notes: *Derived from Kent and Medway 2011 Census data of population aged $\geq 18$ years. **Derived from Kent and Medway $201 \mathrm{I}$ Census data of all ages.

Abbreviation: $\mathrm{n} / \mathrm{a}$, not available.

of the MUR), with few having had reviews following hospital discharge or because they used a specific medicine. A total of 136 respondents $(13.7 \%)$ indicated that they had experienced receiving both advice about new medicines and review of all medicines in a private room.

Most pharmacists provided information on the frequency of providing MUR and NMS, with the former being provided
Table 2 Demographic details of pharmacist responders and pharmacies

\begin{tabular}{|c|c|c|c|}
\hline Characteristic & Number (\%) & $\begin{array}{l}\text { National data derived } \\
\text { from registers (\%) }\end{array}$ & \\
\hline \multicolumn{4}{|l|}{$\operatorname{Sex}(n=338)$} \\
\hline Female & $179(53.0)$ & Female & 40.6 \\
\hline Male & $159(47.0)$ & Male & 59.4 \\
\hline \multicolumn{4}{|c|}{ Years qualified $(n=325)$} \\
\hline$\leq 3$ & $78(24.0)$ & $\begin{array}{l}\text { Registrants in last } 3 \text { years/ } \\
\text { total register }\end{array}$ & 18.8 \\
\hline $4-10$ & $116(35.7)$ & $\begin{array}{l}\text { Registrants in last } 9 \text { years/ } \\
\text { total register }\end{array}$ & 29.3 \\
\hline$>10$ & $|3|(40.3)$ & Remaining registrants & 51.9 \\
\hline \multicolumn{4}{|c|}{ Role in pharmacy $(n=340)$} \\
\hline $\begin{array}{l}\text { Manager/sole } \\
\text { pharmacist }\end{array}$ & $269(79.1)$ & Owner/employee & 76 \\
\hline Second pharmacist & $22(6.5)$ & & \\
\hline Superintendent & $13(3.8)$ & & \\
\hline Locum & $36(10.6)$ & Locum & 24 \\
\hline \multicolumn{4}{|c|}{ Type of pharmacy $(n=340)$} \\
\hline $\begin{array}{l}\text { Large chain } \\
\text { ( } \geq 31 \text { pharmacies) }\end{array}$ & $223(65.6)$ & National multiple & 55 \\
\hline $\begin{array}{l}\text { Medium chain } \\
(1 \mathrm{I}-30)\end{array}$ & $19(5.6)$ & Other multiple & 15 \\
\hline Small chain $(2-10)$ & $33(9.7)$ & Chain of $\leq 4$ pharmacies & 29 \\
\hline Single pharmacy & $65(19.1)$ & & \\
\hline \multicolumn{2}{|c|}{ Location of pharmacy $(n=338)$} & $\mathrm{n} / \mathrm{a}$ & \\
\hline $\begin{array}{l}\text { High street/ } \\
\text { suburban }\end{array}$ & $116(34.3)$ & & \\
\hline $\begin{array}{l}\text { Shopping precinct/ } \\
\text { out of town center }\end{array}$ & $37(10.9)$ & & \\
\hline Rural/village & $80(23.7)$ & & \\
\hline Supermarket & $31(9.2)$ & & \\
\hline $\begin{array}{l}\text { Attached to GP } \\
\text { surgery }\end{array}$ & $49(14.5)$ & & \\
\hline Other & $25(7.4)$ & & \\
\hline \multicolumn{4}{|c|}{ Number of MURs in the previous month $(n=299)$} \\
\hline 0 & $15(5.0)$ & $95 \%$ of CPs provide MURs & \\
\hline $1-10$ & $36(12.0)$ & & \\
\hline $11-20$ & $44(14.7)$ & & \\
\hline $21-35$ & $95(31.8)$ & & \\
\hline $36-50$ & $75(25.1)$ & & \\
\hline$\geq 5$ । & $34(11.4)$ & & \\
\hline \multicolumn{4}{|c|}{ Number of NMS in the previous month $(n=303)$} \\
\hline 0 & $39(12.9)$ & $80 \%$ of CPs provide NMS & \\
\hline $1-10$ & $179(59.1)$ & & \\
\hline $\mid \mathrm{I}-20$ & $56(18.5)$ & & \\
\hline $21-35$ & $24(7.9)$ & & \\
\hline$\geq 36$ & $5(1.7)$ & & \\
\hline
\end{tabular}

Abbreviations: CP, community pharmacy; GP, general practitioner; n/a, not available; NMS, New Medicines Service; MURs, Medicine Use Reviews.

more frequently (Table 2). The majority of the pharmacists providing data $(275 / 294 ; 93.5 \%)$ indicated that they had conducted some target MURs in the past month: $258(87.8 \%)$ to people taking high-risk medicines and $251(85.4 \%)$ to those using respiratory medicines, but only $75(25.5 \%)$ 
Table 3 Experiences of and willingness to use medicines-related services among the public

\begin{tabular}{|c|c|c|c|}
\hline \multirow[t]{2}{*}{ Service/aspect of service } & \multirow[t]{2}{*}{$\begin{array}{l}\text { Had experience } \\
\text { of MRS, } n(\%)\end{array}$} & \multicolumn{2}{|c|}{$\begin{array}{l}\text { Would be prepared to use } \\
\text { MRS in the future, } \mathbf{n}(\%)\end{array}$} \\
\hline & & Yes & Maybe \\
\hline \multicolumn{4}{|l|}{ Received advice concerning medicines just collected } \\
\hline In private consultation room & $288(28.8)$ & $695(69.6)$ & $216(21.6)$ \\
\hline In quiet area of pharmacy & $325(32.5)$ & $732(73.3)$ & $203(20.3)$ \\
\hline Across pharmacy counter & 708 (70.9) & $820(82.1)$ & $132(13.2)$ \\
\hline \multicolumn{4}{|l|}{ Received advice concerning new medicine just collected } \\
\hline In private consultation room & $194(19.4)$ & $700(70.1)$ & $215(21.5)$ \\
\hline In quiet area of pharmacy & $213(21.3)$ & $732(73.3)$ & $201(20.1)$ \\
\hline Across pharmacy counter & $510(5 \mathrm{I} .0)$ & $80 I(80.2)$ & $146(14.6)$ \\
\hline \multicolumn{4}{|l|}{ Had a discussion with a pharmacist: } \\
\hline Because recently discharged from hospital & $102(10.2)$ & $655(65.6)$ & $219(21.9)$ \\
\hline Because were taking particular medicine & $230(23.0)$ & $710(7 I .1)$ & $226(22.6)$ \\
\hline A general review in a private consultation room & $248(24.9)$ & $685(68.9)$ & $233(23.4)$ \\
\hline \multicolumn{4}{|l|}{ Given pharmacist permission to: } \\
\hline Telephone you to follow-up about advice already provided & III (II.I) & $544(54.5)$ & $235(23.5)$ \\
\hline Share your information with local NHS & $116(11.6)$ & $553(55.4)$ & $232(23.2)$ \\
\hline Share your information with your doctor & $345(34.6)$ & $808(8 \mathrm{I} .0)$ & $132(13.2)$ \\
\hline
\end{tabular}

Abbreviations: MRS, medicines-related service; NHS, National Health Service.

targeted people recently discharged from a hospital. The median time taken to provide a MUR was estimated at 10 minutes (range 2-40; $\mathrm{n}=306$ ), median time to recruit to the NMS was 5 minutes (range $1-20 ; n=298$ ), first consultation 8 minutes $(1-30 ; n=264)$, and follow-up consultation 5 minutes $(1-20 ; \mathrm{n}=262)$.

\section{Willingness to use services}

Over $90 \%$ of the public showed willingness to use services in future (Table 3), but the proportion favoring receiving advice across the counter was higher than for a private room. Willingness to have a discussion with a pharmacist because of recent hospital discharge was lower than other reasons for doing so, and while $94.2 \%$ (940) were willing to allow sharing of information with their doctor, only $78.6 \%$ (785) indicated their willingness to allow data sharing with the local National Health Service and 78.0\% (779) to allow a pharmacist to provide telephone follow-up. For all the aspects of services, respondents who were frequent pharmacy users and those using regular medicines were significantly more willing to agree than those not using pharmacies or medicines regularly (all $P<0.001$ ).

A majority of the public $(717 ; 71.8 \%)$ indicated their willingness to make an appointment for a medicines-related service and $72.0 \%$ (718) to wait for 10 to 15 minutes to see a pharmacist (Table 4). In contrast, significantly fewer pharmacists considered that people would be willing to make appointments $(161 ; 47.2 \% ; P<0.001)$ and the majority $(191 ; 56.0 \%)$ felt that people would wait no more than
5 minutes. However, perceptions concerning discussion time with a pharmacist were more closely aligned, with $59.0 \%$ of pharmacists (193) and 47.8\% (477) of the public viewing no more than 15 minutes as acceptable.

\section{Reasons for using pharmacy medicines- related services}

There were 167 members of the public who indicated that they were worried about medicines-related problems for

Table 4 Pharmacist and public perceptions concerning aspects of service provision

\begin{tabular}{|c|c|c|c|}
\hline $\begin{array}{l}\text { Perceived willingness } \\
\text { concerning: }\end{array}$ & $\begin{array}{l}\text { Pharmacists, } \\
\text { n (\%) }\end{array}$ & $\begin{array}{l}\text { Public, } \\
\text { n (\%) }\end{array}$ & $P$-value \\
\hline \multicolumn{4}{|c|}{ Time waiting to talk to the pharmacist } \\
\hline No more than 5 minutes & 191 (56.7) & $196(19.6)$ & $<0.001$ \\
\hline No more than 10 minutes & III (32.9) & $370(37.1)$ & \\
\hline No more than 15 minutes & $32(9.5)$ & $348(34.9)$ & \\
\hline More than 15 minutes & $3(0.9)$ & $83(8.3)$ & \\
\hline $\begin{array}{l}\text { Making an appointment to } \\
\text { talk to the pharmacist } \\
\text { (\% indicating yes) }\end{array}$ & $161(48.1)$ & $717(7 \mid .8)$ & $<0.001$ \\
\hline \multicolumn{4}{|l|}{ Time waiting for an appointment } \\
\hline No more than 4 hours & $47(15.1)$ & $137(\mid 3.8)$ & $<0.001$ \\
\hline No more than I day & $86(27.6)$ & $379(37.9)$ & \\
\hline No more than 4 days & $45(14.4)$ & $168(16.9)$ & \\
\hline No more than I week & $104(33.3)$ & $259(26.0)$ & \\
\hline More than I week & $30(9.6)$ & $52(5.2)$ & \\
\hline \multicolumn{4}{|c|}{ Time spent talking to pharmacist } \\
\hline No more than 5 minutes & $44(13.5)$ & $168(16.7)$ & 0.01 \\
\hline No more than 15 minutes & $193(59.0)$ & $477(47.8)$ & \\
\hline No more than 30 minutes & $64(19.6)$ & $216(21.6)$ & \\
\hline More than 30 minutes & $26(8.0)$ & $137(\mid 3.7)$ & \\
\hline
\end{tabular}


themselves or people they cared for. The most frequent cause for worry was side effects, cited by 78 , followed by difficulties in remembering dosage regimens (23), concerns over lack of efficacy (13), and the overall number of medicines and the need for these (14). Over two-thirds of respondents (690) indicated that they would consider going to a pharmacy for advice if they did experience problems with a medicine. The majority of the remainder (251) indicated that they would go to their general practitioner (GP) instead. Reasons for choosing to see a GP were given as: greater GP knowledge of them personally, and health or illness in general (13), pharmacist not being able to help/change medicines (11), and expectation of being referred to GP by pharmacist (8).

Potential reasons for choosing to use a formal service (MUR or NMS) were offered to both groups (Figure 1). Almost all pharmacists thought the main reason for using one of these services would be "because the pharmacist asked" (94.9\%), which was selected by proportionately fewer members of the public (68.7\%). Significantly fewer pharmacists $(57.5 \%)$ than members of the public $(76.0 \%)$ thought people would use a service "because they had problems with their medicines." "Wanting to help the pharmacist out" was selected as a reason by $53.2 \%$ of the public, compared with $22.6 \%$ of pharmacists.

While most $(274 ; 80.4 \%)$ pharmacist respondents considered that patients needed medicines advisory services, only $186(55.2 \%)$ felt they were wanted. Sixty pharmacists $(17.6 \%)$ thought that different or additional services or changes to the existing formal services were needed.
Among these, eight suggested services needed were monitoring of patients for blood pressure, INR, and other parameters, and four public health services. Eight pharmacists suggested increasing the scope of the NMS to all medicines and 18 suggested changes to the MUR service, which included increased GP involvement, facilitating domiciliary MURs, and ensuring that services are based on need. Several pharmacists also felt that patients may not perceive benefits from the current services. Examples of comments are given in Table 5.

\section{Awareness of MUR and NMS}

Pharmacists considered that people would be more aware of the MUR service than the NMS: 132 (38.7\%) pharmacists thought that at least one-half of their customers would have heard of the MUR, but only 16 (4.7\%) felt this about the NMS. Actual awareness among the public was indeed low, with only $18.2 \%$ (182) having heard of the MUR when it was described to them and 8.6\% (86) of the NMS. Awareness of both services was significantly higher among people who indicated that they had experienced an MUR $(52.0 \%$; 129 experiencing review of all medicines vs 7.1\%; 53 not experiencing) or an NMS (29.9\%; 58 in those experiencing vs $3.5 \%$; 28 not experiencing). Respondents with experience of an MUR were also more aware of the NMS than those without it (18.5\% 46 vs 5.1\% 38). Regular medicine users were more aware of both the MUR $(147 ; 24.3 \%)$ and NMS (62; 10.2\%), compared with $9.1 \%$ (36) and 6.1\% (24) in nonmedicine users, respectively.

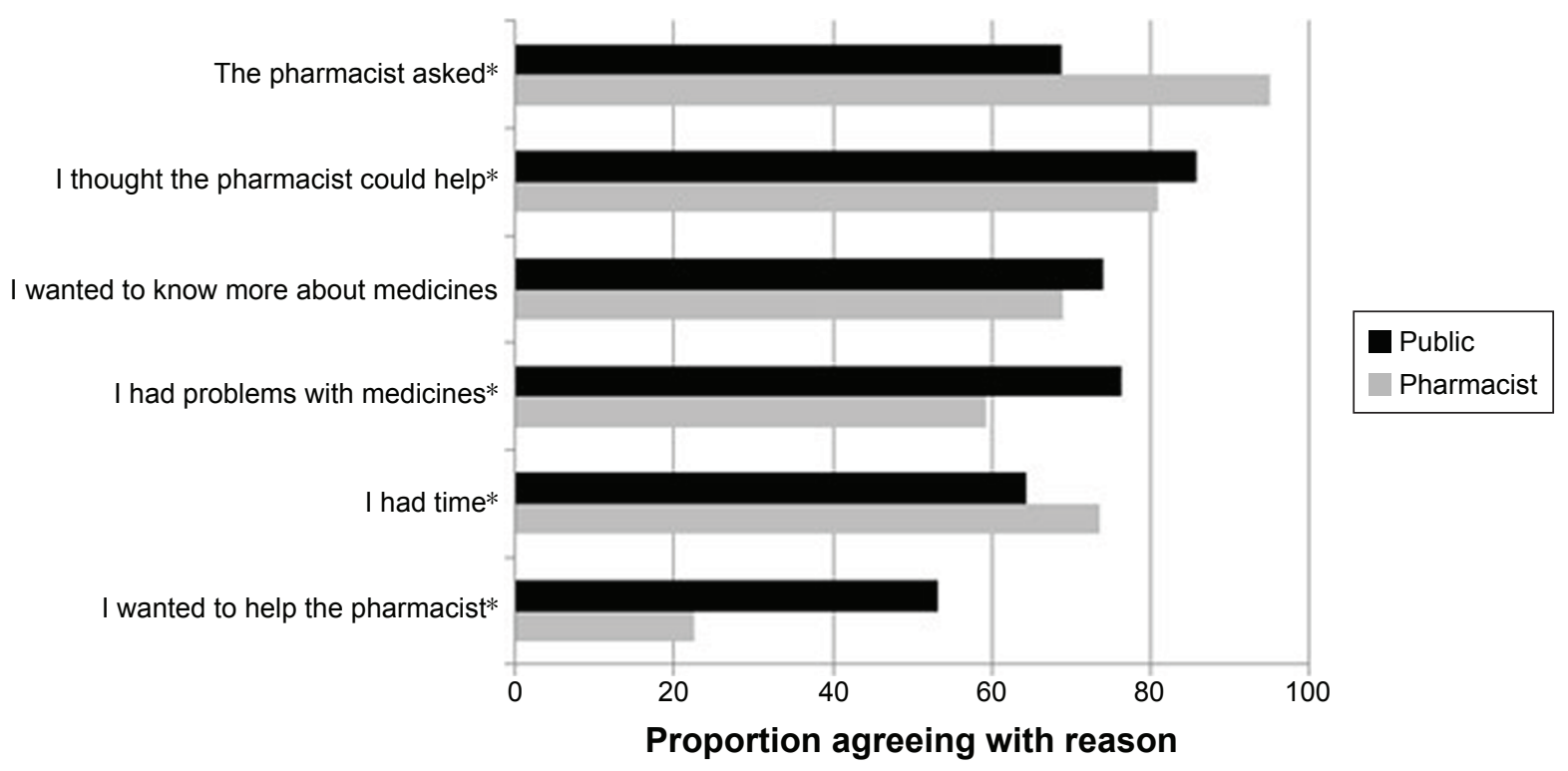

Figure I Potential reasons for using medicines-related service identified by pharmacist and the public. Notes: *Difference between pharmacist and public views; $P<0.001 \chi^{2}$ test. 
Table 5 Examples of views expressed by pharmacist and public respondents on medicine advisory services

\begin{tabular}{|c|c|c|}
\hline Respondent & Comment & Characteristics \\
\hline \multirow[t]{11}{*}{ Pharmacist views } & There is little connection between prescriber/pharmacist with both & Male manager/sole pharmacist in \\
\hline & MUR and NMS. It would be better with MURs if patients were required & large multiple pharmacy \\
\hline & to have them prior to a clinical review by GP and then prescriber could & \\
\hline & undertake their review with feedback information to hand. With the NMS & \\
\hline & a formal direction to enter the service should be made by prescribers and & \\
\hline & pharmacists should feed back to the prescribers postintervention & \\
\hline & MURs and NMS are now a means for increasing pharmacy revenue, we & Female locum in small chain pharmacy \\
\hline & are hounded daily to do MURs and NMS by head office, we are told to do & \\
\hline & easy ones that don't take long, they are no longer about patient's needs & \\
\hline & but how much we get for them! & \\
\hline & $\begin{array}{l}\text { At the moment MUR and NMS very rarely lead to optimization of } \\
\text { medicine management and patients often question what was the point of it }\end{array}$ & $\begin{array}{l}\text { Female manager/sole pharmacist in } \\
\text { medium chain pharmacy }\end{array}$ \\
\hline \multirow[t]{6}{*}{ Public views } & $\begin{array}{l}\text { Can trust pharmacists more after these experiences. More knowledge - } \\
\text { easier access for help than GP }\end{array}$ & $\begin{array}{l}\text { Male, } 34 \text { or younger, on no regular } \\
\text { medicines }\end{array}$ \\
\hline & A pharmacist has more knowledge than I thought and seems more willing & Male, 65 or over, using more than \\
\hline & to help and is not as patronizing as some GPs & eight medicines \\
\hline & Pharmacists do a lot more than before, they do not just dispense but they & Female, 65 or over, using up to four \\
\hline & also make sure that I take my medication correctly and ask how I feel. & medicines \\
\hline & The pharmacist also makes sure that I visit the doctor when I need to & \\
\hline
\end{tabular}

Abbreviations: GP, general practitioner; MUR, Medicine Use Review; NMS, New Medicines Service.

Fewer than half the pharmacists $(46.3 \%$; 155$)$ thought that patients agreeing to undergo an MUR knew its purpose, whereas more than one-half thought that this was the case for the NMS $(57.9 \% ; 194)$.

\section{Expectations and experiences of benefits from medicines-related services}

Expectations of benefit from receiving medicines services among the public were relatively high, with overall $>70 \%$ indicating that they would expect general benefit, that the pharmacist would help them know more about their medicines, understand how to use their medicines better, and encourage them to use medicines as prescribed (Table 6). Willingness to use both the MUR and NMS was positively associated with expectation of general benefit, as well as willingness to make an appointment and to wait longer to speak to the pharmacist $(P<0.001)$. A higher proportion of pharmacists than the public were positive about all expected benefits, except for increasing adherence, which was perceived as an expected benefit by proportionately more of the public. Expectations related to sorting out problems and reducing the number of medicines/waste were relatively low in both groups.

Both groups perceived actual benefits attained to be lower than potential benefits, with pharmacists again being more likely to perceive benefits than the public, even among regular medicine users (Table 6).

There were 689 respondents who had experienced a benefit from a pharmacy medicine service, $28.0 \%$ (193) of whom considered their relationship with the pharmacist changed as a result, $34.6 \%$ (218) felt that their view of pharmacists as health care professionals changed, and $35.4 \%$ (244) felt that their awareness of pharmacists' knowledge about medicines changed, with the remainder indicating no change.

Table 6 Public and pharmacist expectations and experiences of medicines-related services

\begin{tabular}{|c|c|c|c|c|c|}
\hline \multirow{2}{*}{$\begin{array}{l}\text { Medicines reviews with a pharmacist } \\
\text { help people to: }\end{array}$} & \multicolumn{2}{|c|}{ Expectations* } & \multicolumn{3}{|l|}{ Experiences** } \\
\hline & Public (\%) & Pharmacists (\%) & All public (\%) & Regular medicine users (\%) & Pharmacists (\%) \\
\hline Benefit in general & $78 \mathrm{I}(78.2)$ & $293(89.3)$ & $550(55.3)$ & $428(7 I .2)$ & $265(83.9)$ \\
\hline Know more about medicines & $729(72.9)$ & $275(83.1)$ & $44 \mid(44.2)$ & $343(56.8)$ & $236(73.8)$ \\
\hline Understand better how to use medicines & $757(75.7)$ & $282(86.0)$ & $480(48.2)$ & $369(6 I .3)$ & $270(84.1)$ \\
\hline Encourage medicines use as doctor expects & $774(77.5)$ & $230(70.1)$ & $5 \mathrm{I} 5(5 \mathrm{I} .7)$ & $396(65.8)$ & $185(57.5)$ \\
\hline Sort out problems & $612(61.2)$ & $26 I(79.3)$ & $298(29.9)$ & $243(40.4)$ & $223(70.1)$ \\
\hline Order fewer medicines/reduce waste & $44 I(44 . I)$ & $175(53.2)$ & $158(\mid 5.8)$ & $138(22.9)$ & $135(42.2)$ \\
\hline
\end{tabular}

Notes: *Differences between pharmacist and public expectations were all significant $(P<0.00 \mathrm{I})$. **Differences between pharmacist and public experiences were significant $(P<0.001)$ with the exception of encouraging medicine use as per doctor expectations. 
In total 260 respondents provided additional comments on their experiences of services, 75 of whom indicated that their appreciation of what a pharmacist could offer had changed as a result (Table 5). Many respondents also indicated that they would use a pharmacist more readily, offering reasons such as ease of access and greater knowledge about medicines than GPs. Users of services showed increased awareness of pharmacists' knowledge and potential to benefit them personally, but there was also greater awareness that pharmacists can help with using medicines more than in the past.

\section{Discussion}

The majority of the public have received advice about medicines in community pharmacies across the counter and are happy with this, whereas few have received advice in a private consultation room. Both pharmacist and public surveys indicated that MURs are provided more often than NMS, in line with national statistics. The public were willing to use these services, although there was less willingness to allow telephone follow-up, an option for NMS follow-up consultations. Both pharmacists and the public reported that MURs after hospital discharge were infrequent, and willingness to use this service among the public was also low. The time taken to provide an MUR was estimated by pharmacists as $\sim 10$ minutes and NMS as 12 minutes, which align with both pharmacist and public perceptions of how much time people are willing to spend talking to a pharmacist about their medicines.

The results confirm pharmacist-driven service provision, almost all pharmacists, and nearly $70 \%$ of the public indicating pharmacist invitation as a reason for using formal services. It is concerning that over half the public saw wanting to help the pharmacist as another reason for accepting an invitation and that over half the pharmacists considered patients did not know the purpose of the MUR when they agreed to it. Awareness of both MUR and NMS was low among the public, even in regular medicine users, confirming previous qualitative work, ${ }^{16,17}$ hence the need for pharmacists to invite people to use services. The low uptake of postdischarge MURs and willingness to use this service has been shown previously, ${ }^{21}$ and efforts are being made to increase this, involving hospital pharmacists. ${ }^{22}$

Although around two-thirds of people would consider going to a pharmacy for advice about medicines-related problems, a substantial proportion prefer to talk to their GP, primarily due to low expectations that the pharmacist would be able to resolve problems. This was supported by infrequent experiences among the public of problems being resolved, in contrast to pharmacist views, most of whom perceived services to benefit recipients. Our data suggest that formal cognitive services can change peoples' perceptions of pharmacists and also that using one service may increase awareness, thus potential use, of other services. Consultations with a pharmacist increase the likelihood of seeking advice again, although, as here, most people prefer to discuss medicines with their doctor. ${ }^{23}$

The formal services in England were developed with little involvement of patients or public and are aimed primarily at enhancing patient knowledge, understanding, and adherence and, for the MUR, reducing waste. Improving adherence and reducing waste/reordering were, however, considered by both groups as least likely to be achieved. Our data, which concur with the Australian experience, ${ }^{12}$ suggest that worries about side effects are among the most common concerns people have about medicines, thus perhaps greater emphasis should be placed on this aspect of medicines during consultations. Relatively little research has explored what people really want from pharmacist-provided medicines-related services, most studies determine views on existing services, and few compare consumer and pharmacist views. ${ }^{24-27}$ As found here, Australian work shows low public awareness of medicines-related services ${ }^{24}$ and differences in views. ${ }^{25}$ Australian pharmacists overestimated the importance of being available for consultations and providing advice on minor ailments. Our work showed that pharmacists underestimated the willingness of the public to both wait to speak to them and make appointments for services. Misunderstanding of pharmaceutical care services between pharmacists and patients and divergence in perceived benefits, as well as in frequency of information provision, have also been found. ${ }^{26,27}$

More work is needed to determine what services are desired by patients and the public and how they should be delivered. Our study suggests that pharmacists providing formal services should determine the willingness of potential users to make appointments and make use of this to engage them more effectively in preparing for their consultation, perhaps by providing leaflets in advance. This could ensure that those who take up the services are those who really perceive a potential for benefit or have problems they wish to discuss with a pharmacist and thus may lead to increased user experiences of benefits.

\section{Strengths and limitations}

Both surveys were developed from the findings of qualitative work, however no psychometric testing was carried out. Both achieved relatively good response rates in comparison with other studies involving these groups, although the 
pharmacist survey required two reminders. The surveys were administered in the same area of England at the same time and the respondents were reasonably representative of their respective populations. Equivalent questions were used to enable comparisons between pharmacists and public. Data on service provision, obtained to assess sample representativeness, were self-reported. Both surveys may be subjected to recall bias and in addition, the public survey was interviewerassisted, so may include an element of obsequiousness bias.

\section{Conclusion}

The public is willing to use community pharmacy medicinesrelated services, but many people prefer to discuss problems with a doctor. Perceptions of pharmacists and the public differed with respect to reasons for using services, willingness to wait to see a pharmacist and to make appointments, as well as expected and perceived benefits of services. For services to improve, the pharmacy profession needs a better awareness of what the public, especially those with potential to benefit from services, view as acceptable and desirable. Professional pharmacy organizations and pharmacists themselves also need to make use of these findings to encourage greater uptake of services through promotion and explanation of their potential benefits.

\section{Disclosure}

The authors report no conflicts of interest in this work.

\section{References}

1. Health and Social care Information Centre. Available from: http://www/ hscic.gov.uk. Accessed April 21, 2015.

2. Latif A, Boardman H. Community pharmacists' attitudes towards medicines use reviews and factors affecting the numbers performed. Pharm World Sci. 2008;30(5):536-543.

3. Latif A, Pollock K, Boardman H. The contribution of the Medicines Use Review (MUR) consultation to counselling practice in community pharmacies. Patient Educ Couns. 2011;83(3):336-344.

4. Krska J, Nesbit J, Baylie K, O'Kane A. Patient views on the MUR service. Int J Pharm Pract. 2009;17(Suppl 1):A41-A42.

5. Iqbal S, Wood K. Exploring patient opinions of MURs. Int J Pharm Pract. 2011;18(Suppl 2):20.

6. Youssef S. Do patients perceive benefit from a structured warfarin MUR? Int J Pharm Pract. 2009;17(Suppl 2):B62-B63.

7. Latif A, Boardman H, Pollock J. Reasons involved in selecting patients for a MUR: exploring pharmacist and staff choices. Int J Pharm Pract. 2011;19(Suppl 1):31-32.

8. Wilcock M, Harding G. What do pharmacists think of MURs and do they change prescribed medication? Pharm J. 2008;281:163-167.

9. Bissell P, Blenkinsopp A, Short D, Mason L. Patients' experiences of a community pharmacy-led medicines management service. Health Soc Care Community. 2008;16(4):363-369.

10. Elliott R, Boyd M, Waring J, et al. Understanding and appraising the New Medicines Service in the NHS in England (029/0124). Available from: http://www.nottingham.ac.uk/ pazmjb/nms/downloads/report/ index.html\#2/z. Accessed October 2, 2015. (Archived by WebCite ${ }^{\circledR}$ at http://www.webcitation.org/6bydND1cL.)
11. McMillan S, Kelly F, Sav A, King MA, Whitty JA, Wheeler AJ. Consumer and carer views of Australian community pharmacy practice: awareness, experiences and expectations. $J$ Pharm Health Serv Res. 2014;5:29-36.

12. Carter SR, Moles R, White L, Chen TF. The effect of experiencing medication-related worry and the social influence of the general practitioner on consumer willingness to use a pharmacist-provided medication management service. Res Social Admin Pharm. 2012;8(6):e21.

13. Montgomery AT, Kälvemark Sporrong S, Manap N, Tully MP, Lindblad AK. Receiving a pharmaceutical care service compared to receiving standard pharmacy service in Sweden how do patients differ with regard to perceptions of medicine use and the pharmacy encounter? Res Social Admin Pharm. 2010;6(3):185-195.

14. Carter SR, Moles RJ, White L, Chen TF. Patients' willingness to use a pharmacist-provided medication management service: The influence of outcome expectancies and communication efficacy. Res Social Admin Pharm. 2012;8(6):487-498.

15. Smith J, Picton C, Dayan M. Now More than Ever: Why Pharmacy Needs to Act. London: Royal Pharmaceutical Society; 2014.

16. Kember J, Hodson K, James DH. Public perceptions of community pharmacy: a qualitative study. Int J Pharm Pract. 2013;21(Suppl 2):50.

17. Corlett SA, Dodds LJ, Rodgers RM. As pharmacists expand their clinical roles do the general public recognise what they can offer? Pharmacoepidemiol Drug Saf. 2013;22(6):672-673.

18. Mackridge AM, Marriott JF. Information-related roles and pharmacists: public opinion. Abstract presented at: Health Services Research and Pharmacy Practice conference; April 3-4, 2006; Bath, UK.

19. Van den Berg M, Donyai P. How was patient empowerment portrayed in information leaflets describing the community pharmacy Medicines Use Review service in the UK? Patient Educ Couns. 2010; 80(2):274-276.

20. Saramunee K, Krska J, Mackridge AJ, Richards J, Suttajit S, PhilipsHoward P. General public views on pharmacy public health services: current situation and opportunities in the future. Pub Health. 2015;129(6): 705-715.

21. Lam MYY, Dodds L, Corlett SA. Poor uptake of dMURs is not the fault of hospital pharmacy services. Pharmacoepidemiol Drug Saf. 2016;25:12-13.

22. Robinson S. Hospital e-referral initiative boosts post-discharge MURs in community pharmacies. Pharm J. 2015;295.

23. Tinelli M, Bond C, Blenkinsopp A, Jaffray M, Watson M, Hannaford P. On the behalf of the community pharmacy medicines management evaluation team. Patient evaluation of a community pharmacy medications management service. Ann Pharmacother. 2007;41(12):1962-1970.

24. McMillan SS, Wheeler AJ, Sav A, et al. Community pharmacy in Australia: a health hub destination of the future. Res Social Admin Pharm. 2013;9(6):863-875.

25. McMillan S, Kelly F, Sav A, King MA, Whitty JA, Wheeler AJ. Australian community pharmacy services: a survey of what people with chronic conditions and their carers use versus what they consider important. BMJ Open. 2014;4(12):e006587.

26. Assa-Eley M, Kimberlin CL. Using interpersonal perception to characterize pharmacists' and patients' perceptions of the benefits of pharmaceutical care. Health Commun. 2005;17(1):41-56.

27. Puspatasari HP, Aslani P, Krass I. Pharmacists' and consumers' viewpoints on counselling on prescription medicines in Australian community pharmacies. Int J Pharm Pract. 2010;18(4):202-208.

28. Saramunee K, Krska J, Mackridge AJ, Richards J, Suttajit S, PhilipsHoward P. Methodological and economic evaluations of eight survey modes applied to health service research. J Pharm Health Serv Res. 2016;7(1):43-52. Available from: http://onlinelibrary.wiley.com/ doi/10.1111/jphs.12121/abstract. Accessed August 16, 2016. 


\section{Publish your work in this journal}

Patient Preference and Adherence is an international, peer-reviewed, open access journal that focuses on the growing importance of patient preference and adherence throughout the therapeutic continuum. Patient satisfaction, acceptability, quality of life, compliance, persistence and their role in developing new therapeutic modalities and compounds to optimize

clinical outcomes for existing disease states are major areas of interest for the journal. This journal has been accepted for indexing on PubMed Central. The manuscript management system is completely online and includes a very quick and fair peer-review system, which is all easy to use. Visit http://www. dovepress.com/testimonials.php to read real quotes from published authors.

Submit your manuscript here: http://www.dovepress.com/patient-preference-and-adherence-journal 